\title{
OPTICAL TEXTURE AND LINEAR PERSPECTIVE AS STIMULI FOR SLANT PERCEPTION ${ }^{1}$
}

\author{
HOWARD R. FLOCK \\ Dartmouth College
}

\begin{abstract}
Experiments critical of the effectiveness of variables of optical texture in evoking accurate judgments of slant are shown to be inappropriate, inadequate, or deficient. Experiments supporting linear perspective as a stimulus for slant are evaluated. The contention that perceived slant is a function primarily of linear perspective is shown to be oversimplified and hardly adequate to cope with the facts. Some aspects of Flock's theoretical model specifying optical stimuli for slant are discussed.
\end{abstract}

In his criticism of my theoretical paper on visual slant perception (Flock, 1964a), Freeman (1965) claims that variables of surface texture are both ineffectual and unnecessary for the perception of slant. $\mathrm{He}$ argues that all perceived slants are a function primarily of linear outline perspective (contour convergence) and that the greater the linear perspective the greater the judged visual slant. To support his argument he cites two classes of empirical evidence which seem to show that (a) the bounding contours of rectangles, not their in-lying texture, induce perceived slant (Clark, Smith, \& Rabe, 1956a), and (b) surface texture by itself induces considerable underestimates of slant (Gruber \& Clark, 1956; Flock, 1964b, Experiment IX), whereas textureless rectangles in isolation consistently induce rather good judgments of slant (Freeman, in press). In addition, Freeman apparently was dissatisfied with my theoretical model describing potential optical variables for perceived slant.

\section{Textureless Rectangles versus Surface Texture}

Clark et al. (1956a) found that surface texture by itself $(b=.23 \text {; in } 1956 \mathrm{~b}, .24)^{2}$

1 This work was supported by National Science Foundation Grant GB 2474.

2 In order to make the results of different experiments comparable, I have expressed their results in the form of regression coefficients, $b$, taking the regression of mean judged slant over the " $k$ " levels of physical slant employed by the experimenter $(E)$. is a less-effective condition for accurate slant judgments than is a rectangle by itself $(b=.34$ and $.30 ;$ in $1955, .42$ and .44). Moreover, adding texture to a textureless rectangle does not change the judgment of slant $(b=.36)$. These studies are faithfully described by Dember (1961) who seems to accept the general conclusion in favor of outline convergence, More recently Smith (1964, Conditions $A$ and $B$ ) replicated the earlier findings and again found that textured and textureless rectangles do equally well ( $b=.67$ and .68 ).

Using Clark et al.'s (1956a) arrangement of apparatus, Gruber and Clark (1956) tested the effects on slant judgments of surface texture in isolation. They varied distance of surface, diameter of texture elements (white dots), and separation of texture elements. Regression coefficients based on extrapolations from a partial graphic report of their data varied between .18 and .43 depending on distance, dot density, and dot size.

More recently Epstein (1962), Epstein and Mountford (1963), and Freeman (in press) have found that small, textureless

In the many cases where $E$ used just one physical slant, $0^{\circ}$ slant was added gratuitously on the assumption that had the surface been at $0^{\circ}$ slant, subjects' $\left(S \mathrm{~s}^{\prime}\right)$ judgments would have been centered on $0^{\circ}$. When there is an identity relation between the levels of judged and physical slant, $b=1.0$, and the judgments are assumed to be optimal. When $b=0$, judgments are at a chance level. 
TABLE 1

Angular Parameters in 10 Experiments

\begin{tabular}{|c|c|c|c|c|c|c|c|c|c|c|c|c|c|c|}
\hline \multicolumn{3}{|c|}{ Es and experimental conditions } & \multirow{2}{*}{$\begin{array}{c}\begin{array}{c}\text { Display } \\
\text { surfaces }\end{array} \\
\mathrm{T}\end{array}$} & \multirow{2}{*}{$\frac{\begin{array}{c}V \\
\text { (in deg.) }\end{array}}{10.4}$} & \multirow{2}{*}{$\frac{\left.\begin{array}{c}\mathrm{D} \\
\text { (in } \mathrm{m} .\end{array}\right)}{1.63}$} & \multirow{2}{*}{$\frac{\underset{\mathrm{E}}{\mathrm{inm}})}{6}$} & \multirow{2}{*}{$\frac{\stackrel{\mathrm{s}}{(\mathrm{in} \mathrm{mm} .})}{11}$} & \multirow{2}{*}{$\frac{{ }^{\theta}}{\text { (in deg.) }}$} & \multirow{2}{*}{ (in deg.) } & \multirow{2}{*}{$\frac{\begin{array}{c}\beta_{\mathrm{N}}-\beta_{\mathrm{F}} \\
(\mathrm{min} \text { of } \\
\text { arc) }\end{array}}{-}$} & \multirow{2}{*}{$\frac{\begin{array}{c}\delta \mathrm{N} \\
\text { (min. of } \\
\text { arc) }\end{array}}{13.57}$} & \multirow{2}{*}{$\frac{\begin{array}{c}\delta \mathrm{r} \\
\text { (min. of } \\
\operatorname{arc})\end{array}}{11.63}$} & \multirow{2}{*}{$\frac{\begin{array}{c}\delta \mathrm{N}-\delta \mathrm{F} \\
\min . \text { of } \\
\operatorname{arc})\end{array}}{1.93}$} & \multirow{2}{*}{$\begin{array}{c}b \\
.23\end{array}$} \\
\hline Clark et al. & $1956 a$ & B & & & & & & & & & & & & \\
\hline Clark et al. & $1956 \mathrm{~b}$ & B & $\mathrm{T}$ & 10.4 & 1.63 & 6 & 11 & 40 & - & - & 13.57 & 11.63 & 1.93 & .24 \\
\hline Clark et al. & $1956 a$ & $\mathrm{C}, \mathrm{D}$ & $\mathrm{R}$ & 20.2 & 1.63 & - & - & 40 & 9.8 & 36. & 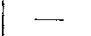 & - & 一 & $.34, .30$ \\
\hline Clark et al. & $1956 a$ & $\mathrm{E}$ & $\mathrm{T}-\mathrm{R}$ & 20.2 & 1.63 & 6 & 11 & 40 & 9.8 & 36. & 13.36 & 11.97 & 1.39 & .38 \\
\hline Clark et al. & 1955 & & $\mathrm{R}$ & 20.2 & 1.63 & - & - & $0,20,40$ & 9.8 & 36. & $\cdots$ & - & - & .42 \\
\hline Clark et al. & 1955 & & $\mathrm{R}$ & 20.2 & 1.63 & - & 一 & $0,20,40$ & 6.7 & 24. & - & - & - & .44 \\
\hline Smith & 1964 & A & $\mathrm{R}$ & 32.5 & 2.25 & - & - & $0,15,30,45,60$ & 6.4 & 29. & - & 一 & - & .67 \\
\hline Smith & 1964 & B & $\mathrm{T}-\mathrm{R}$ & 32.5 & 2.25 & 6 & $13^{\mathrm{b}}$ & $0,15,30,45,60$ & 6.3 & 29. & 9.63 & 8.74 & .88 & .68 \\
\hline \multirow[t]{11}{*}{ Gruber et al. } & 1956 & I & $\mathrm{T}$ & $7 . \mathrm{a}$ & 6. & 3 & $8^{b}, 16^{b}$ & $32,43,53$ & - & 一 & 1.85 & 1.58 & .28 & $.24, .20$ \\
\hline & & & & & 6. & 6 & $8^{b}, 16^{b}$ & $32,43,53$ & 一 & - & 3.71 & 3.15 & .56 & $.22, .23$ \\
\hline & & & & & 3. & 3 & $8^{b}, 16^{b}$ & $32,43,53$ & - & - & 3.71 & 3.15 & .56 & $.27, .25$ \\
\hline & & & & & 4.5 & 3 & $8^{b}, 16^{b}$ & $32,43,53$ & - & 一 & 2.47 & 2.10 & .37 & $.25, .19$ \\
\hline & & & & & 4.5 & 6 & $8^{b}, 16^{b}$ & $32,43,53$ & - & - & 4.95 & 4.20 & .74 & $.28, .29$ \\
\hline & & & & & 3. & 6 & $8^{b}, 16^{b}$ & $32,43,53$ & 一 & 一 & 7.42 & 6.31 & 1.11 & $.28, .34$ \\
\hline & & & & & 1.5 & 3 & $8^{b}, 16^{b}$ & $32,43,53$ & - & - & 7.42 & 6.31 & 1.11 & $.24, .21$ \\
\hline & & & & & 1.5 & 6 & $8^{b}, 16^{b}$ & $32,43,53$ & - & - & 14.84 & 12.61 & 2.23 & $.33, .43$ \\
\hline & & II & $\mathrm{T}$ & 15.9 & 1.38 & 6 & $6^{\mathrm{b}}$ & 43 & 一 & - & 16.73 & 12.88 & 3.86 & .28 \\
\hline & & & & & & & $30^{\mathrm{b}}$ & 43 & 一 & 一 & 16.73 & 12.88 & 3.86 & .35 \\
\hline & & & & & & & $90^{\mathrm{b}}$ & 43 & - & - & 16.73 & 12.88 & 3.86 & .18 \\
\hline Smith & 1956 & $\mathrm{~A}, \mathrm{C}$ & $\mathrm{R}$ & 20.2 & 1.63 & 一 & - & $0,10,20,30,40,50$ & 9.8 & 43. & - & - & - & $.41, .44$ \\
\hline Smith & 1959 & A & $\mathrm{R}$ & 21.4 & 1.73 & - & - & $0,10,25,40$ & 9. & 30. & - & 一 & - & .35 \\
\hline Epstein & 1962 & NR & $\mathrm{R}$ & $?$ & 1.5 & - & 一 & $15,30,45,60$ & .97 & .65 & - & $\cdots$ & - & .59 \\
\hline
\end{tabular}

a Rectangular aperture.

parameters. 
Table 1-Continued

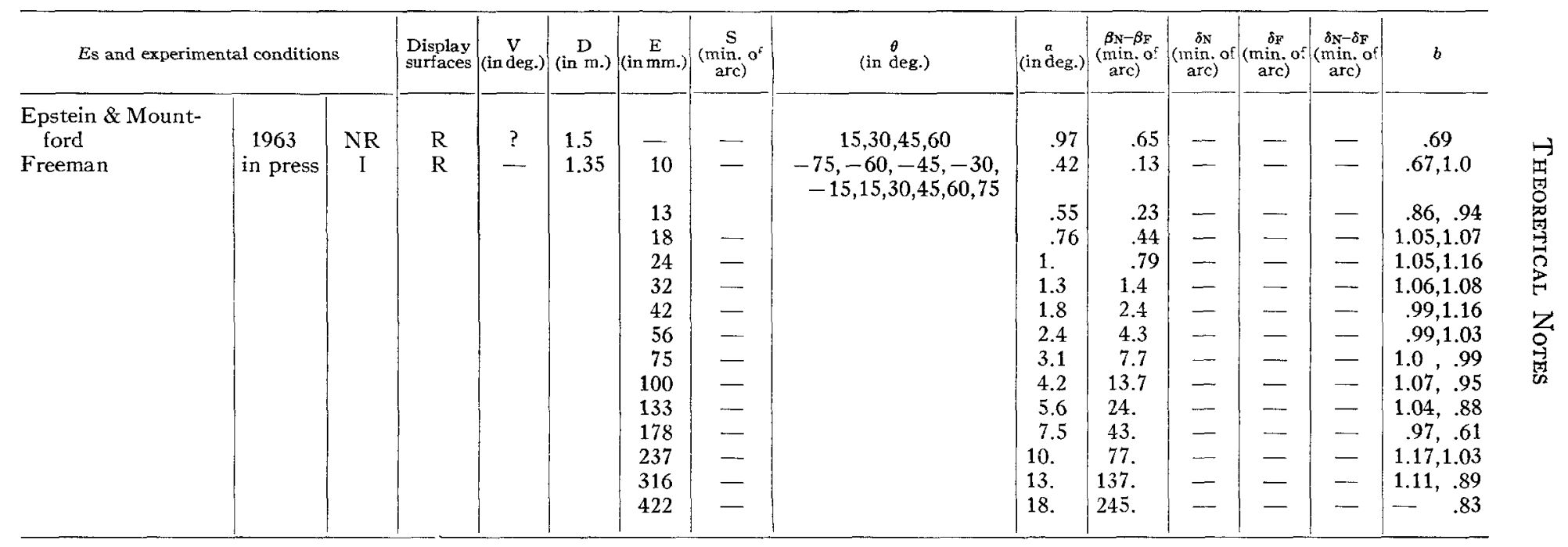


rectangles under complete reduction conditions yield almost perfect slant judgments. Epstein's experiments (Conditions NR) yielded coefficients of .59 and .69. Freeman's experiments yielded a total of 45 coefficients of regression of mean judged slant over 10 levels of physical slant, varying from .67 to 1.17 with a near-perfect mean and median of 99 .

At the superficial level that I have described these data, it would seem that there might be some basis for Freeman's (1965) claim. But let us look more closely at these experiments cited by Freeman.

\section{TABLE 1}

Some relevant data about these experiments are given in Table 1 . The experimenter $(E)$ and experimental conditions are identified in Columns 1-3. The symbols $T, R$, and $T-R$ in Column 4 indicate that the display was composed of an extended (edges occluded from view) textured surface $(T)$, of a textureless rectangle (R), or of a textured rectangle (T-R). Columns 5-8 give for each experiment the total angular diameter of the field of view (V) in degrees, the distance (D) in meters between the center of the display and the eye, the diameter (E) in millimeters of the texture element, and the separation ( $S$ ) in millimeters from center to center of adjacent texture elements. The symbol $\theta$, in degrees, indicates the actual slants used in an experiment. The symbol $\alpha$ gives the angular height in degrees of the rectangle when at $0^{\circ}$ slant, measured along the meridian perpendicular to the axis of rotation. The column labeled $\beta_{\mathrm{N}}-\beta_{\mathrm{F}}$ provides a rough measure of linear perspective, $\beta_{\mathrm{N}}$ being the angular width in minutes of arc of the slanted rectangular edge nearest the eye and $\beta_{\mathbf{F}}$ in minutes of arc of the edge farthest from the eye when the rectangle was at the most extreme slant used by that $E$. Columns 12 and 13 give the angular widths, $\delta$, in minutes of arc of the nearest (subscript $\mathrm{N}$ ) and farthest (subscript F) texture element from the eye. These angular widths (sizes) were measured at the meridian that bisects and is perpendicular to the axis of rotation when the surface was at the most extreme slant used by that $E$. The regression coefficient is given as $b$ (see Footnote 2 above).

Except for Freeman's and Epstein's experiments, which will be discussed later, $\beta_{N}-\beta_{\mathrm{F}}$ for the cited experiments varied from 24 to 43 minutes of arc. Moreover, the angular sizes of the rectangles in these experiments varied between $6.3^{\circ}$ and $9.8^{\circ}$. Consider the comparable data for the surface textures that were tested. For the cited experiments $\delta_{\mathrm{N}}-\delta_{\mathrm{F}}$ varied between 16.8 seconds of $\operatorname{arc}$ and 3.8 minutes of arc. Moreover, the angular sizes of the dot elements, $\delta$, were never greater than 16.7 and were as small as 1.6 minutes of arc.

For these experiments, can we be sure that the angular changes in the texture elements over a slanted surface as well as the texture elements themselves were supraliminal for $S \mathrm{~s}$ ? After all, angular changes of .28 minute- 3.8 minutes of arc and even angular white and black dots of 1.6-16.7 minutes of arc would be expected to be subliminal under a variety of viewing conditions for even a normal monocular eye. Despite that, not a single $E$ cited in Table 1 gave a solitary clue about the visual acuity of his $S$ s. Except for Smith (1964), not a single $E$ who tested textures reported any luminance measures for dots and backgrounds. Smith (1964) reported the luminance of the white background but not of the black dots he used. It is not clear, therefore, that there was a discriminable change in the perspective of surface texture in any of these experiments.

That Freeman could have overlooked this crucial question is surprising. For one thing, not only did I discuss the question of surface texture and visual acuity, but I also predicted what Table 1 tends to reveal: that as a term like $\delta_{N}-\delta_{F}$ approaches liminal values, surface texture will be increasingly ineffectual in eliciting good slant judgments (Flock, 1964a, p. 386). Freeman's lapse here is surprising for a second reason. In his own work he attributed the failure of his first experiment to the use of overly small rectangles, even though for those rectangles $\beta_{\mathrm{N}}-\beta_{\mathrm{F}}$ was as large as 7.7 minutes of arc. $\mathrm{He}$ complained that "whatever cues were present in such 
stimuli must have been very weak." s According to Freeman there was no discriminable information in a perspective change of 7.7 minutes of arc when the stimulus object was a rectangle. Why, then, would he expect that there would be discriminable information when the stimulus object was a surface texture and the perspective change was as small as .28 minute- 3.8 minutes of arc?

It is true, then, that in these studies surface texture has not elicited very accurate judgments of slant. But each instance of failure occurred under presumably near-liminal, liminal, or subliminal conditions, involving angularly small dot elements, angularly small changes in dot size, angularly small separations, low dot density, or short exposure and extreme variability of the elements of texture as in Flock's (1964b) Experiment IX. Experimental studies were available in which conditions were more favorable for surface texture, but Freeman seems to have overlooked them. For example, in the paper that he criticized (Flock, 1964a) there were at least three such references (Flock, 1962; Flock \& Moscatelli, 1964; Gibson, 1950).

How effective is the linear perspective of a slanted, textureless, rectangular surface as a stimulus for slant? Is it as effective as Freeman implies? Except for Epstein's (1962), Epstein and Mountford's (1963), and Freeman's (in press) experiments, the untextured rectangular surfaces have been between $6.3^{\circ}$ and $9.8^{\circ}$ in height. For these rectangles all but one of the regression coefficients were between .30 and .44 , the exception being Smith's (1964) coefficient of .67. Curiously, that result of .67 was greater than anything that Smith $(1956,1959)$ or his colleagues had found earlier, even though the experimental conditions were similar in most relevant respects. It would seem, therefore, that supraliminal $6^{\circ}-10^{\circ}$ rectangles at slants up to $40^{\circ}$ and $50^{\circ}$ will reliably yield a coefficient hetween .30 and perhaps .45 . In contrast, threshold conditions for surface texture seem to yield coefficients between .22 and .30. Thus, under relatively optimal

${ }^{3}$ The quoted explanation was made in an earlier edition (Freeman, 1964, p. 17). conditions textureless rectangular surfaces perform only slightly better than do surface textures under threshold conditions.

\section{Freeman's and Epstein's Experiments}

In Table 1 compare the results of Freeman and Epstein with all other Es who have tested the slant-inducing effects of textureless rectangular surfaces. Epstein and Freeman, using smaller rectangles than the other $E_{\mathrm{S}}$ (see $\alpha$ in Table 1 ), get markedly better slant judgments. It is as if the smaller the rectangle, the better slant judgments became." There are some grounds, however, for disregarding the findings of both of these experimenters.

Freeman's (in press) data are, I believe, artifacts of his experimental method. Freeman predicted that if a standard (ST) slanted rectangle was smaller than a comparison (CO) rectangle, then when $S$ adjusted the $\mathrm{CO}$ so that both would have the same perceived slant, $S$ would underestimate the slant of the ST. Moreover, he predicted that the greater the discrepancy in size, the greater the underestimation. Conversely, if $\mathrm{ST}>\mathrm{CO}$, then $S$ would overestimate the slant of the ST. Freeman's data from his second experiment purport to confirm this hypothesis. There are problems, however, in accepting this interpretation. Freeman presented $\mathrm{ST}$ and $\mathrm{CO}$ monocularly in two chambers of a tachistoscope, at time intervals of $\mathrm{ST}=1 \mathrm{sec}-$ ond, rest $=.7$ second, $\mathrm{CO}=1$ second. Both ST and CO appeared in the center of $S$ 's field of view. $E$ changed the slant of the $\mathrm{CO}$ in $2^{\circ}$ steps between trials until, in effect, $S$ reported they were at the same slant. It is not clear, however, that any $S$ s had to see rectangles at a slant in order to confirm Freeman's hypothesis. If $\mathrm{CO}$ was adjusted so that its projected trapezoidal image tended to be similar to that of the ST and so that the two were more or less centered in the field of view, one could predict all of Freeman's curves. In other words, $S$ s'

4 There is a nice irony here. Freeman's (in press) experimental thesis sought to prove that slant judgments became greater as rectangles were made larger. 
tasks as they accepted them may have been to match trapezoids for similarity, rather than slanted rectangles for slant equality.

That Freeman's (in press) data are artifactual is indicated by his disclosure that some of his $S$ s in the first experiment reported that "the stimuli seldom appeared slanted to them." Nevertheless, 25 of the 27 regression coefficients for $S s$ in the first experiment lay between .83 and 1.17 , the other two being .61 and .67. Since $S$ s said they could not see the slant of the rectangles, they must have produced these remarkably good results in some artifactual way as I suggested above. Moreover, if $S$ s could artifactually produce such remarkably good results in the first experiment, could they not artifactually produce the same good results in the second experiment? The second experiment differed from the first in that larger rectangles were used. The results of the second experiment were very similar to the first, 17 of 18 coefficients lying betwen .81 and 1.14 , the 18 th being .76 .

There are other curiosities in Freeman's (in press) article. When the 1 -centimeter rectangle was at $60^{\circ}$ slant, he says that the angle subtended by the nearest edge minus the angle subtended by the farthest edge was 2.5 seconds of arc. Freeman says that this was "well below the limits of visual acuity"; and presumably, therefore, one would expect that $S \mathrm{~s}^{\prime}$ judgments of slant should be $0^{\circ}$. In fact the mean judged slants for the 1 -centimeter rectangle at $60^{\circ}$ slant were $32^{\circ}, 41^{\circ}, 63^{\circ}$, and $58^{\circ}$, of which three are near approximations of the correct slant. Should not Freeman have explained how his $S$ s managed this remarkable feat? (When the rectangles were very small, $S$ s were told the direction of their slant and were both told and shown their true shape and size. $S$ s could then use the ratio of the angular projections of the slanted height to the unslanted width as a clue to the rectangle's slant.)

Epstein's (1962) and Epstein and Mountford's (1963) data should also not be taken too seriously. Epstein photographed a textureless rectangle, size unspecified, from which he made an Ekta- chrome transparency, image size unspecified. The calculations in Table 1 are based on the assumption that, transparencies being about 1 inch, the image height on the transparency was at least 1 inch (although it might have been less). Since the rectangle was the size of a playing card, one might assume that the image width was .8 inch. On the basis of these assumptions $\beta_{\mathrm{N}}-\beta_{\mathrm{F}}$ for slants of $15^{\circ}, 30^{\circ}, 45^{\circ}$, and $60^{\circ}$ was $.20, .35$, .55 , and .65 minutes of arc, respectively. Despite these small perspective changes mean judged slants for the four slant levels were $15^{\circ}, 30^{\circ}, 33^{\circ}$, and $44^{\circ}$ ( $\mathrm{Ep}$ stein, 1962) and $20^{\circ}, 29^{\circ}, 31^{\circ}$, and $54^{\circ}$ (Epstein \& Mountford, 1963). These performances were so remarkably good, one wonders whether artifacts were not present in these experiments also.

On grounds other than these, however, it may be desirable not to take Epstein's data seriously. For part of his 1963 study with Mountford he used trapezoids in a frontal plane as STs, comparing the slant judgments they induced with those induced by physically slanting the transparencies. His trapezoids were wholly incommensurate with the slanted rectangles, however. The trapezoids were projections of much more extremely slanted rectangles than of the slanted rectangles with which they were compared. Although he did refer to these as "slight" discrepancies, that fact did not dissuade him from concluding that frontal trapezoids induced better slant judgments than the slanted rectangles of which they were purported to be the projection. Nor did it persuade him to discard the data and start over again. (Smith, 1964, for example, attempted and failed to replicate his findings.)

\section{Gruber and Clark's Experiment}

Gruber and Clark's (1956) experiment (see above and Table 1 for details) purports to be far more critical of my theoretical position than for the reason given by Freeman (1965, p. 503). Gruber and Clark report only part of their data, in the form of four curves (their Figure 2). The relative position of these curves acquired great significance for Gruber 
and Clark and later for Eriksson (1964). ${ }^{5}$ Gruber and Clark theorized that judged slant depended on a cortical or retinal interaction unrelated to measures of visual acuity. They predicted that dots which are close together or far apart will yield slant judgments that are worse than for dots which are at interim separations. Moreover, they predicted that there would be increasingly accurate slant judgments as one went from extremely small or extremely large to moderate separations. In their second experiment they tested and confirmed these predictions.

Consider the facts, however. Except for their viewing distance of 1.5 meters the total fluctuation over all their mean judged slants was apparently less than $6.5^{\circ}$ (extrapolating from their Figure 2). This range of $6.5^{\circ}$ determined the relative positions of their four curves. Their display of 3-millimeter dots with 8-millimeter separations at 1.5 meters yielded an apparent mean judged slant of $10.1^{\circ}$, whereas their display of 6-millimeter dots with 16-millimeter separations at 3.0 meters yielded an apparent mean judged slant of $14.5^{\circ}$, a difference of $4.4^{\circ}$. These two displays were optically identical. If under the same conditions the same $S$ s vary $4.4^{\circ}$, can one seriously entertain interpretations of four curves based on a total fluctuation among them of $6.5^{\circ}$ ?

In their second experiment they constructed three surfaces each textured with round, white 6 -millimeter dots. The separation of the dots measured from center to center for the three surfaces was 6, 30, and 90 millimeters. A 6-millimeter dot separated by 6-millimeters means that the dots had to be adjacent to each other, leaving an interspace where the dots met of approximately 1.5 millimeters in height and shaped like an equilateral triangle. At the viewing distance of 1,380 millimeters with a field of view of $15.9^{\circ}$ and a single surface slant of $43^{\circ}$, the angular length of that interspace at places farthest from the eye was about 2 minutes of arc. Mean judged slant was $10.4^{\circ}$. Is it not possible that, for some $S$ s over presumably the 48 trials of the experiment, visual acuity for so small an interspace

${ }^{5}$ Most of the criticisms leveled against Gruber and Clark apply equally to Eriksson. could have sometimes been subliminal? For some $S$ s on some trials perhaps the farthest part of the surface, perhaps all of the surface, appeared homogeneous and untextured. Gruber and Clark do not report any data at all about the visual acuity of their $S$ s. They do not report illuminance or dot-background contrast. I would predict that judgments of slant ought to be poor under their conditions. At the other extreme, when dot separation was 90 millimeters, there were 20 dots over the entire display, and mean judged slant was $6.7^{\circ}$. For the interim condition when dot separation was 30 millimeters there were 180 elements over the display, and judged slant was $13.5^{\circ}$. In other words, with an increase in density from 20 to 180 , judged slant improved, as my Equation 4 predicts (Flock, 1964a, p. 383). When dot elements were made so dense that for some $S$ s parts of the surface might have appeared untextured, perceived slant decreased. One hardly need postulate a theory of cortical or retinal interaction to explain that result. Moreover, if their interaction hypothesis depends on the extreme conditions of their second experiment, its relevance to optical variables of texture is debatable.

\section{Limitations of Contour Convergence}

Freeman's reluctance to accept any other variable than the contour convergence of slanted rectangles as a stimulus for perceived slant is hard to reconcile with the facts of man's natural environment. In nature, apart from civilized structures, there seem to be few rectangles and rectangular-like elements. Nevertheless, animals and men (in the jungle, for example) make responses that are neatly attuned to changes in the slants of things, just as if they were correctly perceiving slants. Correspondingly, how does one use linear perspective to explain the following unpublished experiment by Flock and Graves?

An extended surface was constructed with 518 different-sized, different-shaped triangles distributed randomly over it. All surface parameters were normally distributed, and the angular mean height and $\sigma$ of the distribution of shapes at the 
center of the display when the surface was at $0^{\circ}$ slant were $4.5^{\circ}$ and $2.33^{\circ}$, respectively. The surface was placed at six different slants and was seen through apertures of $20^{\circ}, 40^{\circ}$, and $80^{\circ}$. Regression coefficients for the three fields of view with $4.3,19$, and 126 shapes visible at $30^{\circ}$ slant were $.10, .30$, and .69 , respectively. A second group of $S$ s judged the slant of a small $\left(14.03^{\circ}\right)$, medium $\left(32.25^{\circ}\right)$, and large $\left(66.25^{\circ}\right)$ triangle under the same conditions and produced coefficients of $.09, .03$, and -.04 , respectively. Thus, contours of triangles induced no slant regardless of their size, whereas textures composed of small triangles induced slant judgments that became progressively better as field of view was increased. Can Freeman explain these results in terms of contour convergence? It is doubtful that he can explain any slant data in which a rectangle is not presented. His unqualified claim that contour convergence is the stimulus for perceived slant is both oversimplified, because it does not handle all of the available data, and premature, because it is even less capable of coping with the kind of clata just presented.

\section{The Special Case of the Rectangle}

Nowhere have I asserted that the optics of surface texture constitute the stimuli for slant or are the sole determiners of its perception. I have never made any claim for variables of optical texture other than to show that they could explain some old problems in perception. For example, given variables of optical texture, it is not necessary to introduce into space perception many of the subjectivist assumptions with which we have been burdened (see also Flock, 1964c). The theoretical model I have proposed makes it possible to give an account of how perspective cues like linear perspective, size perspective, and motion parallax are related. Freeman's (1965) paper does raise the question, however, of how and whether the isolated slanted rectangle is related to my theoretical formulation. The answer is that the rectangle can be considered an extreme and special case of the formula- tion. There are many aspects of perspective, however, that the theoretical model will not handle. That fact does not mean that either the theoretical model or some event it will not handle is bad, as is implied by Clark et al. (1956b) and Smith (1956) whose taxonomy refers to the elliptical projection of a slanted circle as a "distortion." What it does mean is that the theoretical model has limitations.

In the theoretical model the idea of redundancy of optical information was developed. It was shown that there would be redundant classes of congruent luminous patterns, any one of which would theoretically specify a distal surface slant. These redundant sources of information might refer to a distal rectangle, to the surface texture of that rectangle, or to a specific structural aspect of that surface texture. What makes a particular source of information an effective rather than a potential stimulus for a visual system could depend on a variety of factors, for example, viewing conditions, visual resolving powers, a variety of physiological conditions, instructions, attentional factors, an endless variety of experiental factors, etc. (see Flock, 1963, 1964a ; Flock \& Moscatelli, 1964 ; and for the distinction between potential and effective stimuli, see Gibson, 1960). For these reasons, pitting the force of one class of perspective information against the force of a second, as is favored by many Es cited above, might

${ }^{8}$ With the optic fixation point at the center of the projected trapezoid, with the normal meridian angularly equidistant between the parallel trapezoidal bases and approximately projecting the true axis of rotation, with the great circle arc through the optic fixation point and perpendicular to the normal meridian, it will then be true along the normal meridian and all meridians parallel to it that $(a)$ angular extents of the projected trapezoid will be bilaterally symmetrical on either side of the great circle arc, $(b)$ there will be a gradient of those angular extents along the great circle arc, and $(c)$ therefore Criteria I-IV will be met, although the conditions are special. The slant of the rectangle is then given as specified by the derivation of optical theta (see Flock, 1964a, pp. 384-388). 
yield surprisingly little useful information about the general effectiveness of a particular stimulus for space perceptions.

\section{Physiological Evidence}

Freeman finds in several physiological studies support for contour convergence as the "principal stimulus" for slant. The reasoning $(1965$, p. 503$)$ is that the "visual system is 'tuned' to register contours (abrupt brightness gradients)." Freeman seems to equate linear perspective with all contours and with all brightness gradients. In fact, my lengthy discussion of congruent luminous patterns depends on the assumption that visual systems are tuned to register contours and abrupt brightness gradients (Flock, 1964a, pp. $380-382$ ). How else could the optical texture be registered by the organism?

\section{Flock's EQuation 4}

Freeman (1965, Footnote 2) attributes to this equation peculiar properties, of which negative values is one. But the equation cannot take negative values. The equation depends on the assumption that the parameters of a texture are, if not normally, at least rectangularly distributed (Flock, 1964a, p. 382). Under those conditions it cannot have negative values. Even without such restriction, the conditions under which it could take negative values are very extreme.

Equation 4 should not be considered more than a first statement of the relation between size of visual field, size of element, and variability of elements, on the one hand, and stochastic regularity from the point of view of optics, on the other. Its function at present is a strategic one. Perhaps for the first time three extremely important optical variables have been brought together into a rational relationship. Until the effects of these variables have been empirically tested, their precise relationship must remain unknown.

\section{FLock's EQUatron 5}

According to Freeman (1965, p. 502) "Flock's optical theory of slant encounters its greatest trouble" when it relates the optical slant of the surface to ratios of angles, rather than to the surface's "size, distance, and other variables, as well as slant." He then cites some commonplaces about perspective and implies that they make invalid my Equation $5 . \mathrm{He}$ is incorrect. Equation 5 is invariant over the changes in conditions which he describes. Freeman is simply wrong when he attempts to discuss the mathematics of perspective." Finally, his complaint that the derivation of Equation 5 was not available is unwarranted (Flock, 1964a, Footnote 6).

\section{Sensory Abilities}

Freeman raises questions about the sensory abilities presumed to be necessary for the registration of the optical variables that specify the slant of a surface. Most of the presumed abilities are not very extraordinary. I do want to be explicit about one visual task, however, that is crucial to the assumption that these potential optical variables might be perceptually effective. In the section on "Magnification" I discussed the luminous structure of the optical texture. I suggested that an optical instrument like the eye could scan a small region of the optical texture in some angularly uniform step, register changes in absolute (but averaged) luminances for successive steps, adjust the angular magnitude of the step in scanning a different region of the optical texture, and thereby identify congruent luminous patterns over the optical texture. Whether an eye could make this kind of optical analysis is, of course, an empirical question. Pursuing that empirical question is only one of the

'Consider Freeman's (in press) use of mathematics in his own work. That his Equation 2 is false should be self-evident. For example, letting $a$ and $d$ have reasonable values and letting $c \rightarrow 0, \tan \delta$ should approach 0 . His $\tan \delta$ does not have this property. His statement that $\pi$ is unchanged by the height of the rectangle is self-evident but has absolutely nothing to do with the stimulus at the eye or with his argument. The angular size of $\pi$ at the eye very definitely changes with the height of the rectangle. He then compares $\pi$ with $\delta$, the former being a base angle on a projection plane, the latter being the angular difference of a different event at the eye. For a first-rate analysis of the complexities of perspective, see Gibson (1957). 
possible strategies, however. I have recently been fascinated by the many-sided hypotheses that can be generated from the theoretical model and by the possibility of testing such hypotheses. For example, applying Jameson and Hurvich's (1964) achromatic color theory to the visual problem of identifying congruent luminous patterns in the optical texture, it seems to me that it might be possible to predict systematic errors in slant and distance perception of extended surfaces as a function of changing illuminance and luminance levels. Hypotheses that have been tested and are in the process of being tested have been discussed elsewhere (Flock, 1964a). The data from these tests have not been published as yet, however.

\section{Concluston}

Freeman calls this theoretical model a theory of the stimulus and calls his own a theory of perception. I do not know what is gained by that distinction. Presumably, theories that account for and predict empirical results will flourish, the others will not.

\section{REFERENCES}

Clark, W. C., Smith, A. H., \& Rabe, A. Retinal gradients of outline as a stimulus for slant. Canadian Journal of Psychology, 1955, 9, 247-253.

Crark, W. C., Smith, A. H., \& Rabe, A. The interaction of surface texture, outline gradient, and ground in the perception of slant. Canadian Journal of Psychology, $1956,10,1-8$. (a)

Clark, W. C., Smith, A. H., \& Rabe, A. Retinal gradients of outline distortion and binocular disparity as stimuli for slant. Candian Journal of Psychology, 1956, 10, 77-81. (b)

Dember, W. N. The psychology of perception. New York: Holt, Rinehart, \& Winston, 1961.

Epstein, W. Apparent shape of a meaningful representational form. Perceptual and Motor Skills, 1962, 15, 239-246.

Epstein, W., \& Mountrord, D. Judgment of slant in response to an isolated gradient of stimulation. Perceptual and Motor Skills, 1963, 16, 733-737.

Eriksson, E. S. Monocular slant perception and the texture gradient concept. Scandinavian Journal of Psychology, 1964, 5, 123-128.
FLoCK, H. R. The monocular perception of surface slant. (Doctoral dissertation, Cornell University) Ann Arbor, Mich.: University Microfilms, 1962, No. 62-2514.

FLocK, H. R. Selective registration of information in visual judgments of surface slant. Perceptwal and Motor Skills, 1963, 17, 537-538.

FLock, H. R. A possible optical basis for monocular slant perception. Psychological Review, 1964, 71, 380-391. (a)

F Lock, H. R. Some conditions sufficient for accurate monocular perceptions of moving surface slants. Journal of Experimental Psychology, 1964, 67, 560-572. (b)

FLocK, H. R. Three theoretical views of slant perception. Psychological Bulletin, 1964, 62, 110-121. (c)

Flock, H. R., \& Moscatelli, A. Variables of surface texture and accuracy of space perceptions. Perceptual and Motor Skills, 1964, 19, 327-334.

Freeman, R. B., Jr. The effect of size on judgments of slant. Research Bulletin No. 45, 1964, Department of Psychology, Pennsylvania State University.

FreEMAN, R. B., JR. Ecological optics and visual slant. Psychological Review, 1965, 72, 501-504.

Freeman, R. B., JR. Effect of size on visual slant. Journal of Experimental Psychology, 1966, 71, in press.

Grison, J. J. The perception of visual surfaces. American Journal of Psychology, 1950, 63, 367-384.

Gibson, J. J. Optical motions and transformations as stimuli for visual perception. Psychological Review, 1957, 64, 288-295.

Gibson, J. J. The concept of the stimulus in psychology. American Psychologist, 1960, 15, 694-703.

Gruber, H. E., \& Clark, W. C. Perception of slanted surfaces. Perceptual and Motor Skills, 1956, 6, 97-106.

Jameson, D., \& Hurvich, L. Theory of brightness and color contrast in human vision. Vision Research, 1964, 4, 133-154.

Smitr, A. H. Gradients of outline convergence and distortion as stimuli for slant. Canadian Journal of Psychology, 1956, 10, 211-218.

Smith, A. H. Outline convergence versus closure in the perception of slant. Perceptual and Motor Skills, 1959, 9, 259-266.

Smiтn, A. H. Judgment of slant with constant outline convergence and variable surface texture gradient. Perceptual and Motor Skills, 1964, 18, 869-875.

(Received April 15, 1965) 